\title{
American Stop Smoking Intervention for Cancer Prevention
}

National Cancer Institute

\section{Source}

National Cancer Institute. American Stop Smoking Intervention for Cancer Prevention. NCI Thesaurus. Code C19034.

A tobacco control trial conducted over the 7-year period from 1991-1998. It focused on helping smokers who want to quit, protecting nonsmokers from tobacco smoke, and discouraging the use of tobacco products among children. 